\title{
Morphological and structural properties of amorphous lactulose studied by scanning electron microscopy, polarised neutron scattering, and molecular dynamics simulations
}

\author{
Frederic Ngono ${ }^{1,2}$, Gabriel J. Cuello², Monica Jiménez-Ruiz ${ }^{2}$, Jean-Francois \\ Willart', Mathieu Guerain', Andrew R. Wildes², Anne Stunault' ${ }^{2}$, Cherifa- \\ Mounira Hamoudi-Ben Yelles ${ }^{3}$, Frederic Affouard, ${ }^{1, *}$ \\ ${ }^{1}$ Univ. Lille, CNRS, INRA, ENSCL, UMR 8207 - UMET - Unité Matériaux et Transformations, F-59000 Lille, France \\ 2 Institut Laue Langevin, 71 Av. des Martyrs, CS 20156, F-38042, Grenoble, France \\ ${ }^{3}$ Univ. Lille, Inserm, CHU Lille, U1008 - Controlled Drug Delivery Systems and Biomaterials, F-59000 Lille, France
}

\begin{abstract}
Morphological and structural properties of amorphous disaccharide lactulose $\left(\mathrm{C}_{12} \mathrm{H}_{22} \mathrm{O}_{11}\right)$, obtained by four different amorphisation methods (milling, quenching of the melt form, spray-drying and freeze-drying) are investigated by scanning electron microscopy, polarised neutron scattering and molecular dynamics simulations. While major differences on the morphology of the different amorphous samples are revealed by scanning electron microscopy images, only subtle structural differences have been found by polarised neutron scattering. Microstructure of the milled sample appears slightly different from the others amorphised materials with the presence of remaining crystalline germs which are not detected by X-ray diffraction. Quantitative phase analysis shows that these remaining crystallites are present in a ratio between $1-4 \%$, and their size remains between 20-30 nm despite a long milling time of about 8 hours. The impact of the change in tautomeric concentrations on the physical properties of lactulose in the amorphous state has been investigated from molecular dynamics simulations. It is suggested that chemical differences between lactulose tautomers could be at the origin of small structural differences detected by polarised neutron scattering.
\end{abstract}

Keywords: structure, neutron diffraction, crystallites, amorphous sugar, milling, quenching melt, spray-drying, freeze-drying, molecular dynamics simulation

\footnotetext{
* Corresponding author at: Université Lille Nord de France, F-59655 Villeneuve d'Ascq, France.

E-mail address: frederic.affouard@univ-lille.fr (F. Affouard).
} 


\section{Introduction}

Most medicines (active ingredients and excipients) are mostly formulated in the solid form (tablets, powders for inhalation or lyophilisates) which may actually exist in many physical states ranging from fully ordered, i.e. crystalline, states to fully disordered, i.e. amorphous, states $^{1-3}$. Until now, drugs have been prepared especially in the crystalline state for obvious reasons of stability. However, many pharmaceuticals may also exist in a total or partially amorphous state ${ }^{2}$. The amorphous state particularly exhibits greater dissolution rate ${ }^{4,5}$ compared to the crystalline state and this advantage has been recently used for developing more efficient formulations for poorly-soluble molecules although only a few have actually led to marketed products ${ }^{3}$. Indeed, the amorphous solid state is a quite challenging physical state. Because of its inherent instability ${ }^{6-8}$, it exhibits a slow time evolution of all physical properties and it is capable of recrystallisation which obviously negates the advantages. Physical instabilities ${ }^{8}$ can also lead to uncontrolled chemical instability ${ }^{9-11}$ and greater hygroscopicity which are a significant concern from a pharmaceutical perspective.

In practice, the amorphous state can be actually reached by many different routes ${ }^{12}$. These routes can be classified into three main categories that are distinguished by the different fundamental physical mechanisms involved:

- The mechanical route ${ }^{2,13,14}$ for which the mechanical action can be static as in the case of compression, or dynamic as in the case of mechanical milling ${ }^{15-17}$. The milling consists in the progressive mechanical destruction of the crystalline order until an amorphous disordered solid is obtained. Dehydration of a hydrated crystalline form also falls into this category ${ }^{18,19}$. The main advantage of the mechanical route is that the amorphisation takes place directly in the solid state, i.e. without having to heat the material above its melting point ${ }^{20}$. This route therefore generally allows amorphisation without chemical modification of the material ${ }^{20-22}$. However, it is essential to carry out the milling below the glass transition temperature $T_{g}$ of the material ${ }^{23}$ to avoid the quite rapid recrystallisation of the amorphised fractions. This requires the use of cryomilling when the $T_{g}$ of the material is below ambient temperature.

- The thermal route which consists in melting an initial crystalline material, and then cooling the obtained liquid state rapidly enough to avoid its crystallisation in order to reach the glassy state $^{24,25}$. This route has two intrinsic difficulties. On the one hand, obtaining the liquid phase by melting the crystalline state may often cause uncontrolled and undesirable chemical modifications such as degradation or mutarotation ${ }^{9,11}$. On the other hand, it is not always possible to reach the cooling rate that will allow avoiding the recrystallisation of the liquid. In practice, on an industrial scale, the thermal pathway is often coupled with techniques using mechanical action such as extrusion ${ }^{26}$. So both thermal and mechanical routes are combined. This makes possible to heat the materials to lower temperatures and thus avoid chemical degradation.

- The concentration of a diluted form without crystallisation. The diluted form may be a gas (condensation of a vapour on a cold surface) or a liquid (concentration of a solute in a solution). In the latter case, the most commonly used methods are freeze-drying ${ }^{27}$ and spraydrying $^{28,29}$. Freeze-drying consists in freezing a solution and then sublimating the solvent by applying very low pressures. An amorphous matrix is then obtained. It has a high porosity 3,30 
which is generally very useful for accelerating the re-dissolution of the active ingredient when the drug is administered ${ }^{3,31}$. Spray-drying consists in spraying the solution into fine droplets which are subsequently suddenly dried in a hot gas ${ }^{28,29}$. The drying speed makes it possible to avoid crystallisation and to recover an amorphous and fine powder. This is a simple and fast method allowing the generation of large quantities of amorphous material ${ }^{32}$. It is therefore widely used in the pharmaceutical industry. However, it has the disadvantage, as the freezedrying, to use solvents which may remain in the final product with toxic or plasticising effects $^{27,29}$. Moreover, there are a lot of poorly water soluble drugs for which it is not always possible to find an appropriate solvent.

There are marked differences between the involved transformation processes in the amorphisation techniques ${ }^{12}$. Moreover, the existence of polyamorphism situations in water ${ }^{33,34}$ or possible polyamorphism situations for mannitol ${ }^{35,36}$ have been shown. It is then legitimate to ask whether amorphous products produced by different techniques have discernible physical and chemical characteristics.

Some previous works have studied the effect of the amorphisation method on the physicochemical properties of the formed amorphous compound. For example, Guinet et al. ${ }^{37}$ have found subtle structural modifications between the amorphous states prepared by meltquenching and cryomilling polymorphs I and III of carbamazepine. Surane et al. ${ }^{38}$ have found that spray-dried trehalose does not recrystallise upon heating at $10^{\circ} \mathrm{C} / \mathrm{min}$, while dehydrated dihydrate crystal, quenched-melt and freeze-dried do. The authors have later suggested that this difference of stability may be directly due to the amorphisation method ${ }^{39}$. Similarly, Bhugra et al. ${ }^{40}$ observed from calorimetry measurements that spray-dried sucrose had significantly longer relaxation times than melt quenched or freeze-dried sucrose. By investigating the quinidine, Schammé et al. ${ }^{41}$ have found that the milled crystalline quinidine undergo a sub-Tg cold-crystallisation phenomenon. However the amorphous fraction in the milled compound and the quenched melt compound behave the same way upon scanning calorimetry. Finally, several authors have reported for several amorphous compounds that the kinetics of recrystallisation depend on the chosen amorphisation route $e^{7,42-46}$.

In the present study, disaccharide Lactulose $\left(\mathrm{C}_{12} \mathrm{H}_{22} \mathrm{O}_{11}\right)$, a widely used compound in the pharmaceutical and food industries ${ }^{47,48}$ has been investigated. This sugar has the advantage to be easily amorphised by different amorphisation techniques (milling, quenching melt, spraydrying and freeze-drying) and also possesses a high glass transition temperature $\mathrm{Tg}=86^{\circ} \mathrm{C}^{49}$ which makes it stable for a long time after preparation. It is thus a model of choice to compare the properties of the amorphous states obtained by different amorphisation routes. In addition, as many other sugars $\left(\right.$ glucose $^{50}$, lactose $\mathrm{e}^{51}$, galactose $\mathrm{g}^{52}$, fructose $\mathrm{e}^{50}$ ), lactulose exhibits mutarotation $^{53}$ and three different tautomers (see Figure 1), named here tautomer A (galactosyl $\beta$-furanose), tautomer B (galactosyl $\alpha$-furanose) and tautomer C (galactosyl $\beta$ pyranose) are able to co-exist in the crystalline and amorphous solid states. Their fractions differ from one amorphous compound to another, and from the anhydrous crystal to the trihydrate one ${ }^{54}$. Lactulose thus also offers an interesting opportunity to investigate the chemical changes induced by the different amorphisation routes. 
By means of scanning electron microscopy, polarised neutron diffraction experiments and molecular dynamics simulations, the present investigation focuses on the impact of the amorphisation process on morphological and structural properties of the different amorphous samples. The chemical differences of those amorphous compounds as well as their impact on the molecular mobility are shown in another article ${ }^{55}$.
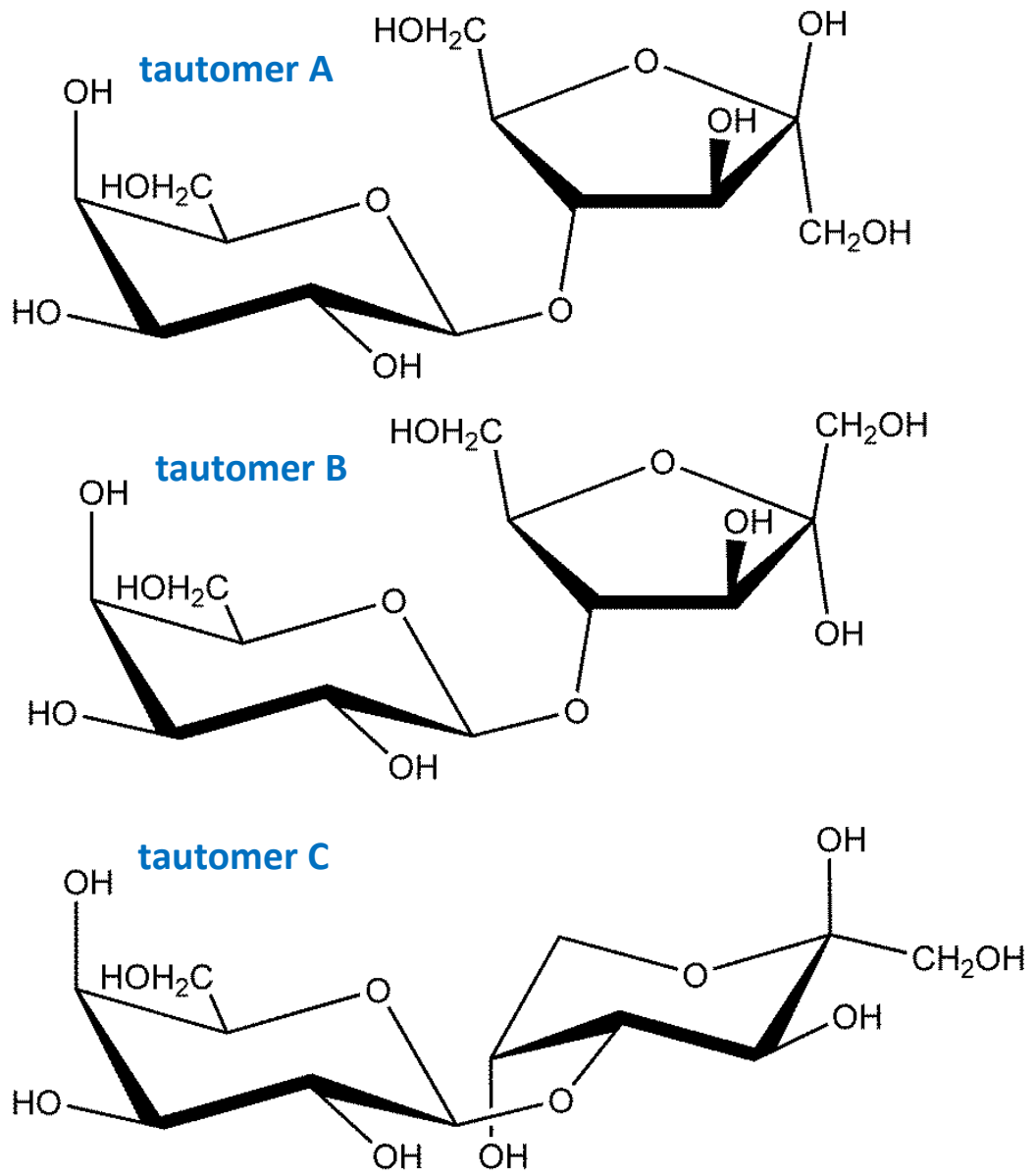

Figure 1: Chemical structures of the three main disaccharide lactulose $\left(\mathrm{C}_{12} \mathrm{H}_{22} \mathrm{O}_{11}\right)$ tautomers $\mathrm{A}, \mathrm{B}$ and $\mathrm{C}^{53}$. 


\section{Experimental and simulation details \\ 2.1 Material}

Crystalline anhydrous lactulose was purchased from Sigma Aldrich. Thermogravimetric experiments have shown that it contains about $3.5 \%$ of water inclusions. The commercial form was thus slightly crushed to favour water release, and dried at $70{ }^{\circ} \mathrm{C}$ during $15 \mathrm{~min}$. The obtained sample has been checked to be totally crystalline, and has been used for the different experiments.

\subsection{Preparation methods}

We used four different techniques to prepare amorphous lactulose compounds: quenching from the melt, ball milling, spray-drying and freeze-drying. The amorphous samples obtained using these techniques will be respectively noted QM, MIL, SD and FD in the following.

a- Quenching from the melt

We heated the crystalline material to $170^{\circ} \mathrm{C}$, i.e. just above its melting temperature $\left(T_{m}=\right.$ $161^{\circ} \mathrm{C}$ ), in order to avoid thermal degradation as much as possible ${ }^{56}$. We subsequently quenched $\left(10^{\circ} \mathrm{C} / \mathrm{min}\right)$ the obtained liquid to room temperature (RT). The whole process was performed inside the differential scanning calorimeter to control the melting process better.

\section{b- Ball milling}

We performed ball-milling in a cold room at $-10^{\circ} \mathrm{C}$ under a dry atmosphere $(\mathrm{RH} \sim 0 \%)$ using a high-energy planetary mill (Pulverisette 7-Fritsch, Idar-Oberstein, Germany). We used $\mathrm{ZrO}_{2}$ milling jars of $43 \mathrm{~cm}^{3}$ with seven balls $(\phi=15 \mathrm{~mm})$ of the same material. We placed $1 \mathrm{~g}$ of material in the planetary mill corresponding to a ball-sample weight ratio of 75:1, and we set the rotation speed of the solar disk to $400 \mathrm{rpm}$, corresponding to an average g-force of the milling balls of 5 . We took care to alternate milling periods (typically $15 \mathrm{~min}$ ) with pause periods (typically $15 \mathrm{~min}$ ) to limit the mechanical heating of the sample. Crystalline lactulose was milled during $8 \mathrm{~h}$ as this milling time was reported to be long enough to induce a complete amorphisation $^{56}$.

c- Spray-drying

We prepared and equilibrated lactulose solution $(5 \mathrm{~g} / 50 \mathrm{ml})$ in distilled water at $\mathrm{RT}$, then spray-dried using a B-290 mini spray-dryer commercialised by Buchi. The solution was injected into a $0.7 \mathrm{~mm}$ nozzle, at a feed rate of $5 \mathrm{ml} / \mathrm{min}$, with an air flow rate of $601 \mathrm{l} / \mathrm{h}$. The inlet and outlet temperatures were $(120 \pm 2)^{\circ} \mathrm{C}$ and $(70 \pm 5)^{\circ} \mathrm{C}$ respectively.

\section{d- Freeze-drying}

We prepared and equilibrated lactulose solution $(5 \mathrm{~g} / 50 \mathrm{ml})$ in distilled water at RT, then freeze-dried using the Epsilon 2-4 LSC freeze-dryer commercialised by Christ. The solution was first frozen at $-45^{\circ} \mathrm{C}$ during $4 \mathrm{~h}$. This frozen solution was then sublimated at $-20^{\circ} \mathrm{C}$ during 
20h under a pressure of 0.07 mbar. A second desiccation step was done at $35^{\circ} \mathrm{C}$ during $40 \mathrm{~h}$ under a pressure of 0.0014 mbar to remove as much of the remaining water as possible.

Using differential scanning calorimetry (DSC) and powder X-ray diffraction, we have checked and confirmed the amorphous character of each sample before and after the neutron scattering experiments. Experimental details are reported in another paper ${ }^{55}$.

\subsection{Scanning electron microscopy (SEM)}

The morphology of the different samples was studied by SEM using a JEOL JSM-7800F LV microscope. Small amounts of samples were mounted on SEM-specific holder (7 mm size) and covered by a conducting thin chromium layer in order to avoid electronic charging during SEM image acquisition. The samples were observed with SEM under an accelerating voltage of $1.5 \mathrm{kV}$ in the secondary electron mode at 75 to $11000 \mathrm{X}$ magnifications.

\subsection{Neutron diffraction measurements}

We investigated the structure of the different amorphous lactulose samples by using the D3 and D7 diffractometers located at Institut Laue-Langevin (ILL, Grenoble, France). These instruments, using different neutron wavelengths, can cover different momentum transfer $(Q)$ ranges: D3 for the high- $Q$ range (typically [0.8-21] $\left.\AA^{-1}\right)^{57}$ and D7 for the low- $Q$ range (typically [0.4-2.5] $\left.\AA^{-1}\right)^{58}$. Both instruments use polarised neutrons and allow polarisation analysis of the diffracted beams.

On D3, the incident neutron wavelength was $0.5 \AA$, as selected by a Heusler polarising monochromator $\left(\mathrm{Cu}_{2} \mathrm{MnAl}\right.$, single crystal $)$. We collected the powder diffraction data at $\mathrm{RT}$ using an annular vanadium cell with a $1.35 \mathrm{~mm}$ thick sample space. The use of such a sample container allows multiple scattering and attenuation effects to be minimised, as compared to a filled cylinder. We filled the container with approximately $2 \mathrm{~g}$ of sample. During the measurement, a single detector was scanned over a total angular range of $4^{\circ}$ to $120^{\circ}$, with typical data acquisition times of 1-2min/angular step, both neutron spin-flip and non-spin-flip polarisation channels being measured at each step. Therefore, measurements were slow, and we needed about $48 \mathrm{~h}$ to collect data from one sample. We carried out the ancillary measurements (empty instrument, empty cell, vanadium rod) under the same conditions. The data treatment protocol is presented in relevant papers ${ }^{57,59-61}$.

On D7, we used an incident wavelength of $4.8 \AA$, as selected by a pyrolytic graphite monochromator. We collected the powder diffraction data at RT using an annular aluminium cell with $1 \mathrm{~mm}$ thick sample space. With such a cell, the measured transmission was between $80 \%$ and $85 \%$, and the multiple scattering was therefore minimised. We filled the container with approximately $2 \mathrm{~g}$ of sample. During the measurement, the scattered neutron polarisation was analysed by $\mathrm{m}=2.8 \mathrm{Co} / \mathrm{Ti}$ super-mirrors over a $132^{\circ}$ angular range, both spin-flip and non-spin-flip intensities being measured. Roughly $2 \mathrm{~h}$ were needed to collect data from one sample. We carried out the ancillary measurements (empty instrument, empty cell, cadmium- 
filled cell, vanadium rod, quartz rod) under the same conditions. The data treatment protocol is presented in the relevant paper ${ }^{62}$.

\subsection{Simulation details}

We have performed molecular dynamics (MD) simulations using the DLPOLY ${ }^{63}$ package (version 4.07) and the OPLS (Optimised Potentials for Liquid Simulations) force field ${ }^{64,65}$, with the simulation conditions similar to that reported in another paper ${ }^{55}$.

Three systems composed each of only tautomer A, tautomer B or tautomer C (see Figure 1) have been investigated from MD simulations. Each simulation box was generated using the same procedure. First, we build an initial cubic pseudo-crystal box composed of 216 molecules. Then, the box was melted and hyper-quenched as described in another paper ${ }^{55}$. We applied a further equilibration of $1 \mathrm{~ns}$ in the NPT ensemble at $300 \mathrm{~K}$ to the resulting box.

The density in the equilibrated boxes at $\mathrm{T}=300 \mathrm{~K}$ is about $1.45 \pm 0.02 \mathrm{~g} / \mathrm{cm}^{3}$ for tautomers A and $\mathrm{C}$, and $1.46 \pm 0.02 \mathrm{~g} / \mathrm{cm}^{3}$ for tautomer B. These values are consistent with the published density of the crystalline counterpart, $1.53 \mathrm{~g} / \mathrm{cm}^{3} 53$. Indeed, the density of the glassy state usually exceeds $90 \%$ of the density of the crystal close to the glass transition temperature ${ }^{9,66,67}$.

This result is also well in line with data obtained for sucrose ${ }^{68}$ for which there is a good agreement between numerical and experimental values for the glassy state $\left(\rho_{\exp }=1.53 \mathrm{~g} / \mathrm{cm}^{3}\right.$, $\rho_{\text {simul }}=1.54 \mathrm{~g} / \mathrm{cm}^{3}$ ). The lactulose glassy state obtained from MD simulations thus seems physically reasonable.

After equilibration, for the three systems composed each of only tautomer A, tautomer B or tautomer $\mathrm{C}$, a $1 \mathrm{~ns}$ production run was performed in order to produce an MD trajectory used to compute the total static structure factor $S(Q)$ from the following equation ${ }^{69}$ :

$S(Q)=<\left|\rho_{\mathrm{Q}}\right|^{2}>\quad$ Eq. 1

where $\rho_{\mathrm{Q}}$ is the density correlator:

$\left.\rho_{\mathrm{Q}}=\sum_{\alpha} b_{\alpha} \exp \left[\mathrm{i} \boldsymbol{Q} \cdot \boldsymbol{r}_{\alpha}\right)\right] \quad$ Eq. 2

and the sum is over all the atoms $\alpha$ of the system. $b_{\alpha}$ and $r_{\alpha}$ are the coherent scattering length and the position of the $\alpha$ atom, respectively. An average $<>$ over isotropically distributed $\boldsymbol{Q}$ vectors having the same modulus $Q$ (with $\Delta \mathrm{Q}= \pm 0.05 \AA^{-1}$ ) is performed in order to obtain $S(Q)$ for a sample. 


\section{Results}

\subsection{Morphology of the different compounds}

Scanning electron micrographs of the crystal, MIL, SD and FD lactulose are shown in Figure 2. The compounds have different morphologies. Crystalline lactulose particles are disoriented and very faceted. Their sizes range between $10 \mu \mathrm{m}$ and $100 \mu \mathrm{m}$. On the other hand, the MIL lactulose particles have lost the morphology of crystalline particles. The particles have become oval-shaped with smooth surface without any facets, and tend to aggregate. This suggests that they have been amorphised during milling. Their sizes are similar to those of the crystalline particle. The SD lactulose particles are all ovoid with a narrow size distribution, ranging between $1 \mu \mathrm{m}$ and $10 \mu \mathrm{m}$. The smaller size and shape of the SD particles is due to experimental conditions used during spray-drying, in particular the kind of atomizer, the feed concentration and the viscosity of the starting solution ${ }^{70,71}$. The FD lactulose particles look like a broken glass, with flake-like morphology. Their size is around $100 \mu \mathrm{m}$. Some FD particles also have small cavities on their surface resulting from water crystals formed during the freezing stage. Those differences of morphology should impact strongly on dissolution rate $^{72}$, and on thermal behaviour (molecular mobility) as observed for lactose ${ }^{73}$.

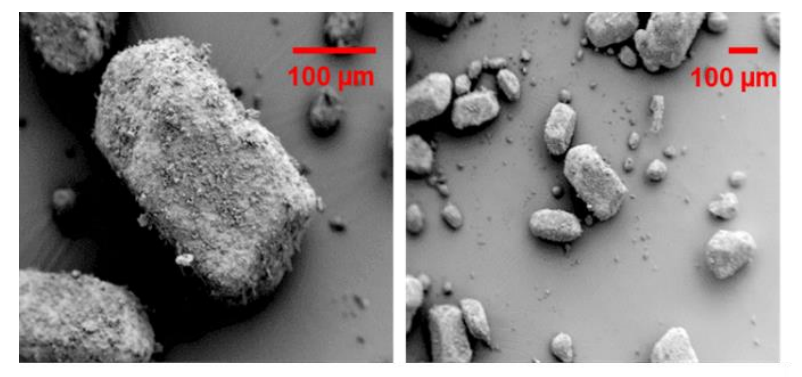

a) Crystal
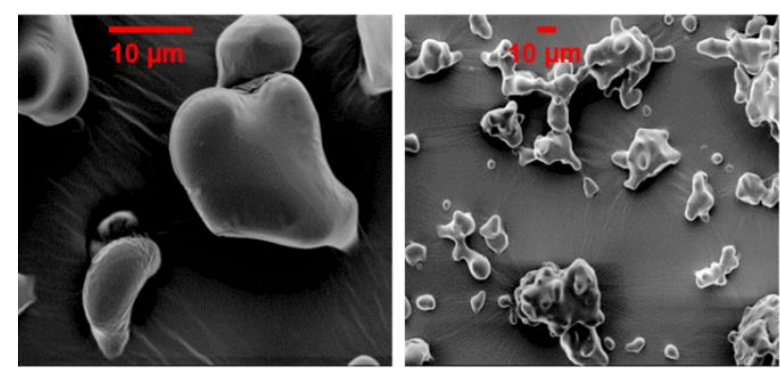

b) MIL
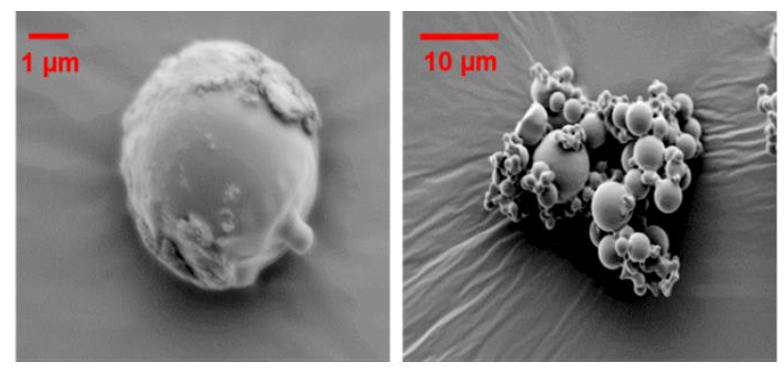

c) SD
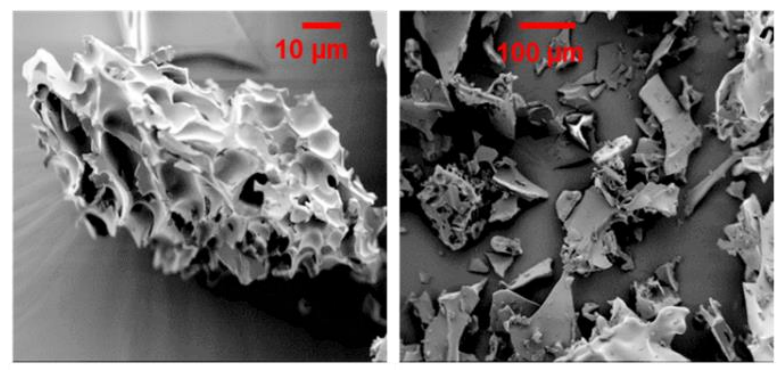

d) FD

Figure 2: Scanning electron micrographs of crystal a), MIL b), SD c), and FD d) lactulose.

\subsection{Polarised neutron scattering and MD simulations}

Little is actually known about local order in amorphous solid materials ${ }^{74}$. Laboratory-based $\mathrm{X}$-ray diffractometers are generally used simply to identify samples as non-crystalline i.e. "Xray amorphous". However, conventional X-ray powder diffraction patterns become broad and 
featureless for crystalline structures on the nanoscale as seen for example for indomethacin and carbamazepin ${ }^{75}$. Neutron diffraction offers a very interesting alternative which allows more subtle structural information to be extracted from the diffraction pattern as will be shown in the following. However, probing structural properties of amorphous hydrogenous samples is quite difficult since their neutron scattering signal contains a huge incoherent contribution due to the high incoherent cross section of hydrogen atoms ( $\sigma_{\text {inc }}=80.27$ barns) compared to the coherent one $\left(\sigma_{\mathrm{coh}}=1.752 \text { barns }\right)^{76}$. This incoherent scattering signal may reach over $90 \%$ of the measured signal as seen in the case of light water $\mathrm{H}_{2} \mathrm{O}^{77}$, and hampers the accurate measurement of the coherent scattering, which contains the structural information. To solve this problem, hydrogenous samples are usually deuterated before neutron diffraction experiments, since $\mathrm{D}\left(\sigma_{\mathrm{inc}}=2.05 \text { barns, } \sigma_{\mathrm{coh}}=1.752 \text { barns }\right)^{76}$ has a much smaller incoherent scattering length than H. Nevertheless, deuteration is usually a very hard and costly task especially for highly hydrogenated samples. Polarised neutrons have thus been used for the diffraction experiment in order to separate the coherent and incoherent intensities experimentally. The data treatment protocol is presented in relevant papers ${ }^{58,59,78}$.

\section{a- Static structure factors in the range $\left(2.5 \AA^{-1}<Q<21 \AA^{-1}\right)$}

Figure 3 shows the static structure factors of all four amorphous lactulose samples obtained from D3.

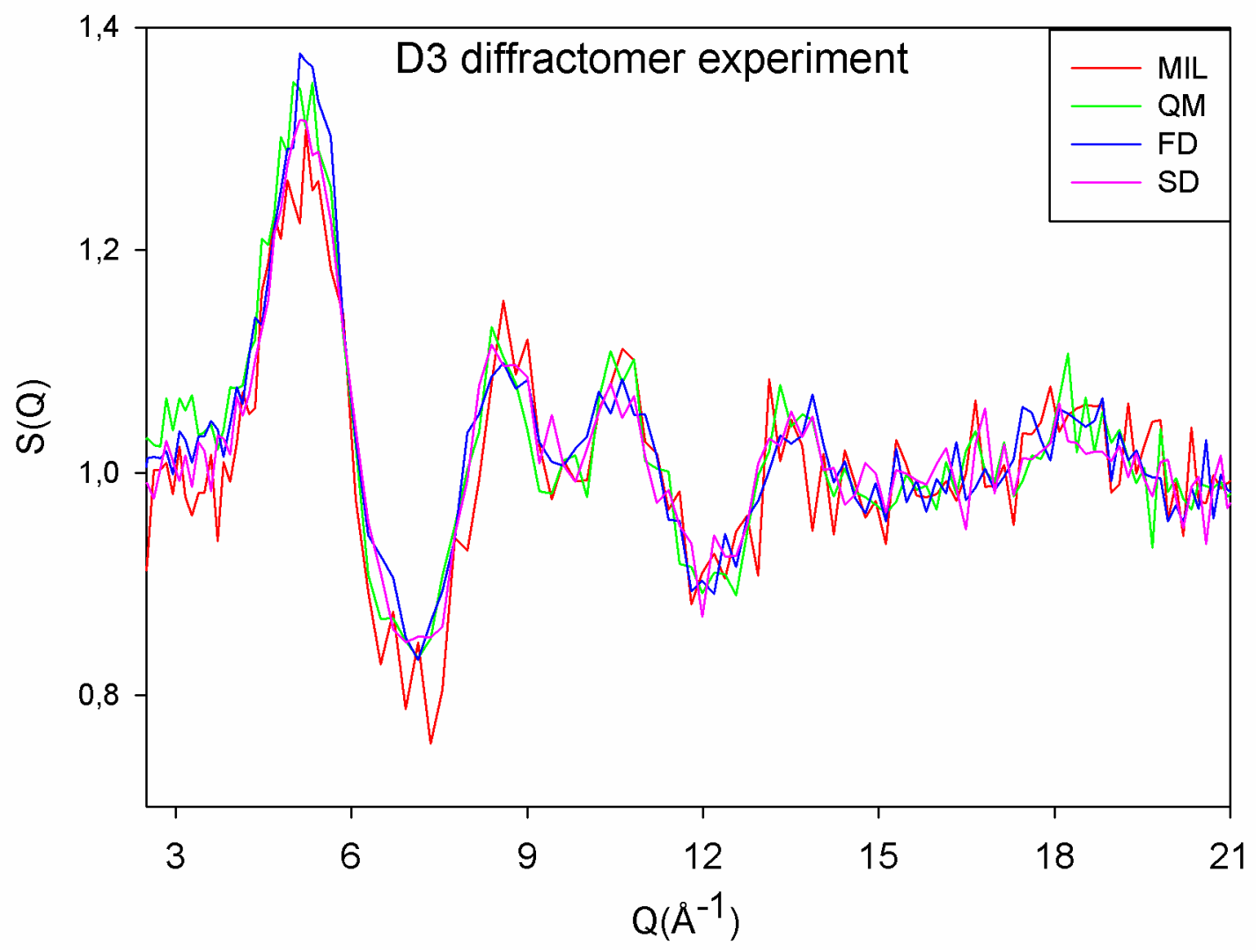


Figure 3: Static structure factors of amorphous lactulose samples: MIL (red line), QM (green line), FD (blue line) and SD (pink line). Each sample was measured at RT on D3, and the measured intensities have been treated to obtain the static structure factors ${ }^{57,59-61}$.

We can consider two main regions in the Figure: a high $Q$-region (above $6 \AA^{-1}$ ) corresponding mainly to intramolecular correlations and a low $Q$-region (from 2.5 to $6 \AA^{-1}$ ) corresponding to a combination of intra/intermolecular correlations. At first glance, within the experimental errors (roughly \pm 0.05 a.u.), the results represented in Figure 3 do not reveal any remarkable difference between the structure factors $S(Q)$ of the different amorphous samples. The signals appear noisy and almost superimposable in the whole range. We could expect differences between structure factors since the different compounds have different tautomeric compositions $^{55}$, and the different tautomers have different molecular structures (see Figure 1). However, those differences fall within the experimental error.

Interestingly, MD simulations can probe the impact of the tautomeric concentration on $S(Q)$ precisely since it is possible to simulate amorphous systems composed of only one type of tautomer. Figure 4 shows the static structure factors of the different tautomers. The experimental static structure factor of an amorphous sample is also added for comparison. Since the experimental static structure factor $S(Q)$ of different amorphous samples are similar, we have arbitrary chosen the FD sample.

In Figure 4, first of all, one can notice that there is an overall fair good agreement between experimental and numerical results, showing that our MD simulations are indeed realistic. The static structure factors of the three different tautomers are identical above $6 \AA^{-1}$. Some slight differences (in the peak position) are found below $6 \AA^{-1}$. In particular between 2.5 and 6 $\AA^{-1}$, the peak is at the same position for tautomers A and B, but at a slightly different position for tautomer $\mathrm{C}$. This difference is likely due to the differences in topology between tautomer $\mathrm{C}$ (two six-membered rings) on the one hand and tautomers $\mathrm{A}$ and $\mathrm{B}$ (one five-membered and one six-membered ring) on the other hand (see Figure 1). The detection of such small structural differences as those between the different tautomers may actually be beyond the capabilities of experimental diffraction methods. 


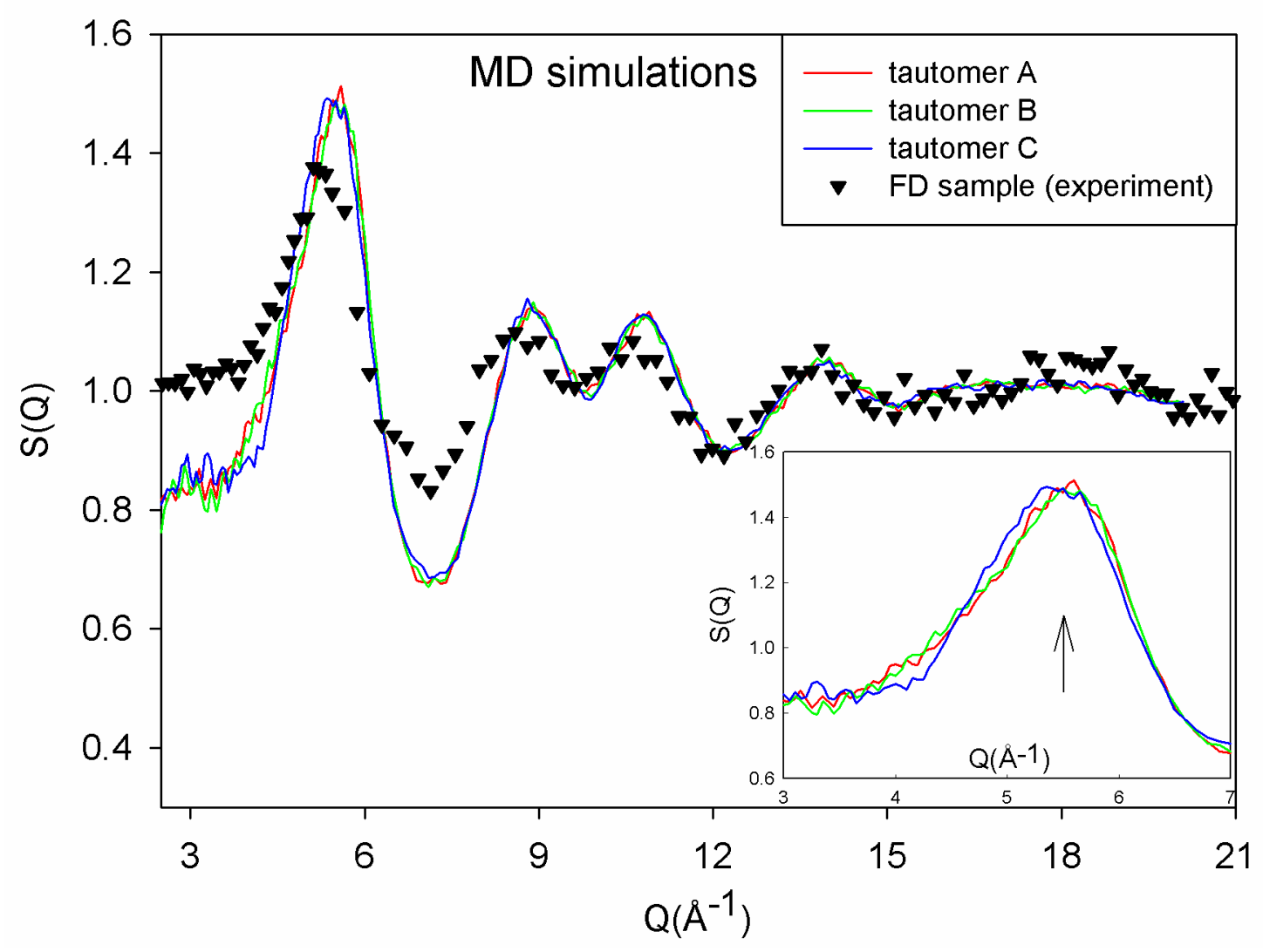

Figure 4: Static structure factors of lactulose tautomer A (red line), tautomer B (green line) and tautomer $\mathrm{C}$ (blue line) calculated using Eq. 1. The error bar on the $\mathrm{Q}$ position as determined by MD simulations is $0.05 \AA^{-1}$. The experimental static structure factor of one of the amorphous samples, arbitrary FD sample (black triangles down), is also included for comparison. The inset shows the low-Q region.

\section{b- Static structure factors at low- $Q\left(Q<2.5 \AA^{-1}\right)$}

Figure 5 shows the static structure factors of amorphous and crystalline lactulose samples obtained experimentally from D7. A similar figure with error bars on $S(Q)$ is represented in Supplementary Material. As expected, the $S(Q)$ of amorphous samples exhibit marked differences with a crystalline powder pattern (see Figure 5). Instead of Bragg peaks, there is a broad first diffraction peak (FDP).

In this $Q$-region, because of the complexity of the molecule, it is difficult to separate inter and intramolecular correlations. Taking into account the size of the lactulose molecule (about 10 $\AA$ ), pure intermolecular contributions are only expected below $Q=2 \pi / r \approx 0.6 \AA^{-1}$. However, the major contribution up to $4 \AA^{-1}$ still comes from intermolecular correlations, as observed from simulations. 
In this Q-region, the patterns measured from all amorphous samples look similar, with FDP around $1.3 \AA^{-1}$. This indicates that the amorphisation technique does not significantly impact the local organisation of the material. It is actually difficult to give a deeper description of the structure of the different amorphous compounds with the D7 diffraction patterns alone, owing to the limited Q-range. Our attempts at PDF (pair distribution function) analysis after combining D3 and D7 diffraction patterns did not give satisfactory results.

We still observe some slight differences between the samples FDP. The FDP could not be fitted using simple functions such as Gaussian, Lorentzian, Voigt or pseudo-Voigt. Therefore, the parameters of those FDPs were estimated as follows: the peak position $\left(Q_{\text {FDP }}\right)$ is calculated as the position of the center of mass of the peak Q-region (from 1.0 to $1.6 \AA^{-1}$ ); the peak width $\left(\Delta_{\mathrm{FDP}}\right)$ is obtained by calculating the distance between both extrema of the derivative plot of the FDP in the peak Q-region; the peak height $\left(A_{\mathrm{FDP}}\right)$ is determined graphically. The results are summarised in Table 1. They show two main information.

Firstly, QM, SD and FD amorphous compounds are similar. The FDP of the QM sample is slightly sharper, suggesting that the local organisation in the QM material is more spatially extended than in the SD and FD compounds. A small difference is also found for the intensity of the FD sample below $1 \AA^{-1}$. For the four investigated amorphous samples, the tautomer $\mathrm{C}$ is in majority in the SD and FD samples, while the tautomer A is in majority in the QM and MIL samples ${ }^{55}$. The tautomeric composition can impact the total structure factor as explained below, and the broadening of the SD and FD peaks compared to the QM peak should be related to a difference in their tautomeric compositions.

Secondly, the MIL sample is quite different to the three other amorphous samples. It has the broadest and highest FDP. Furthermore, two bumps at $0.73 \AA^{-1}$ and $0.90 \AA^{-1}$, and a shoulder at $1.44 \AA^{-1}$ are present on its FDP. They correspond to $Q$ positions close to Bragg peaks in the crystalline powder pattern. Those bumps are not within error bars (see Supplementary Material) and show that the MIL amorphous compound likely includes remaining crystallites as opposed to the other amorphous samples.

Figure 6 compares the diffraction patterns of the MIL and crystalline samples, obtained both by neutron and X-ray diffraction. The low Q bumps are not detected in the X-ray pattern. This absence could be explained by the physical difference between those two techniques, the neutrons being sensitive to the atomic nucleus, and X-ray to the electronic cloud of the atom. The ratio of the peak height between the main peak (at $1.30 \AA^{-1}$ ) of the crystal and those at $0.93 \AA^{-1}$ and $0.65 \AA^{-1}$ are respectively 0.26 and 0.06 for X-ray, and 0.32 and 0.14 for neutrons. Clearly, the peaks are highlighted in the neutron diffraction pattern compared to the X-ray one. Remaining crystalline germs in amorphous compounds are therefore more detectable by neutron diffraction. 


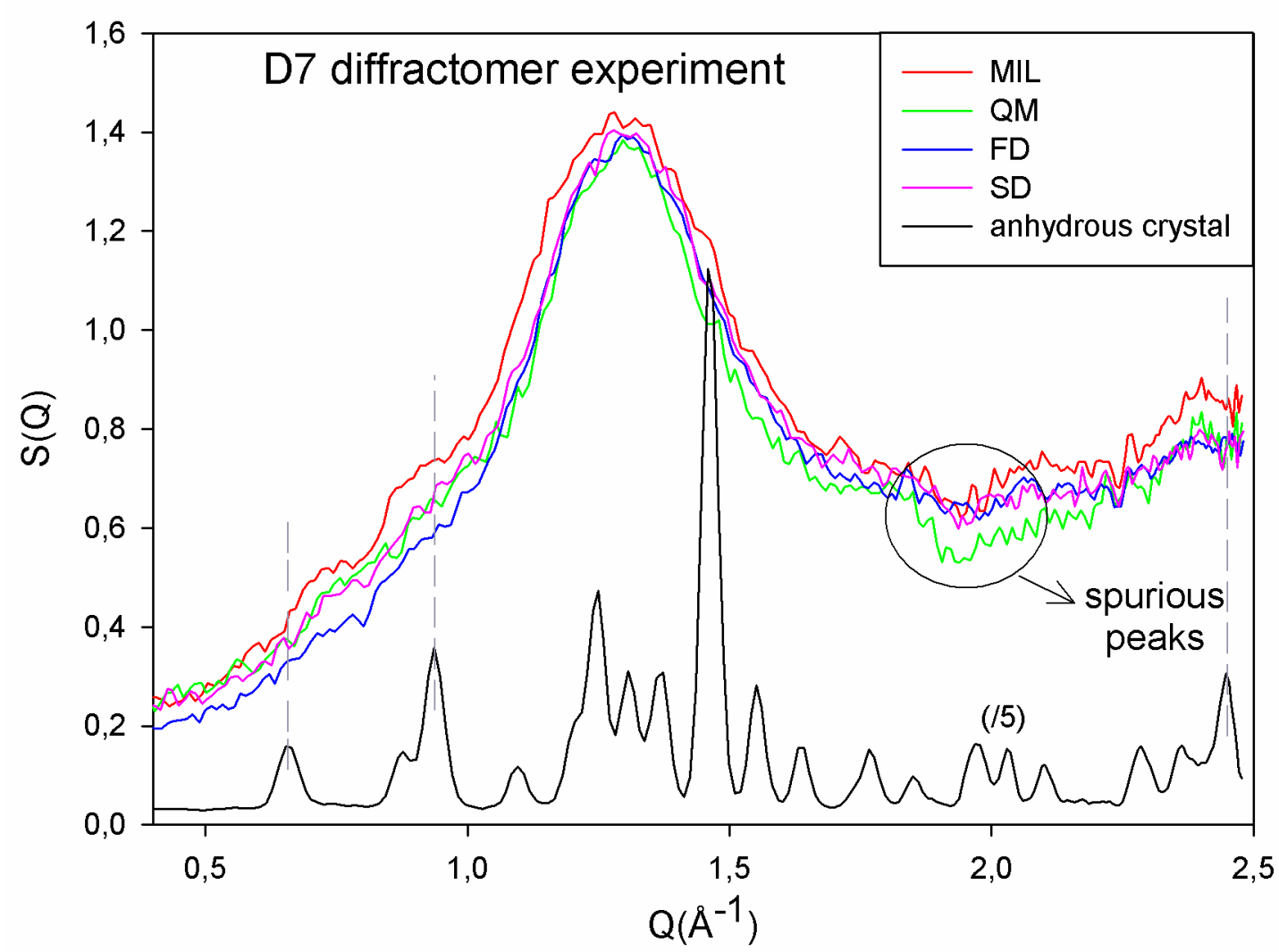

Figure 5: Static structure factors of amorphous and crystalline lactulose samples. Each sample was measured at RT on D7, and the measured intensities were treated to obtain the static structure factors ${ }^{62}$. The patterns of the MIL (red line), QM (green line), FD (blue line), SD (pink line) and anhydrous crystal (black line) lactulose are represented. The pattern of the crystalline lactulose has been divided by 5 compared to that of the amorphous lactulose. All $S(Q)$ present a "dip" around $1.93 \AA^{-1}$; this is an artefact related to the analyser efficiency in that particular Q-range ${ }^{58}$. 

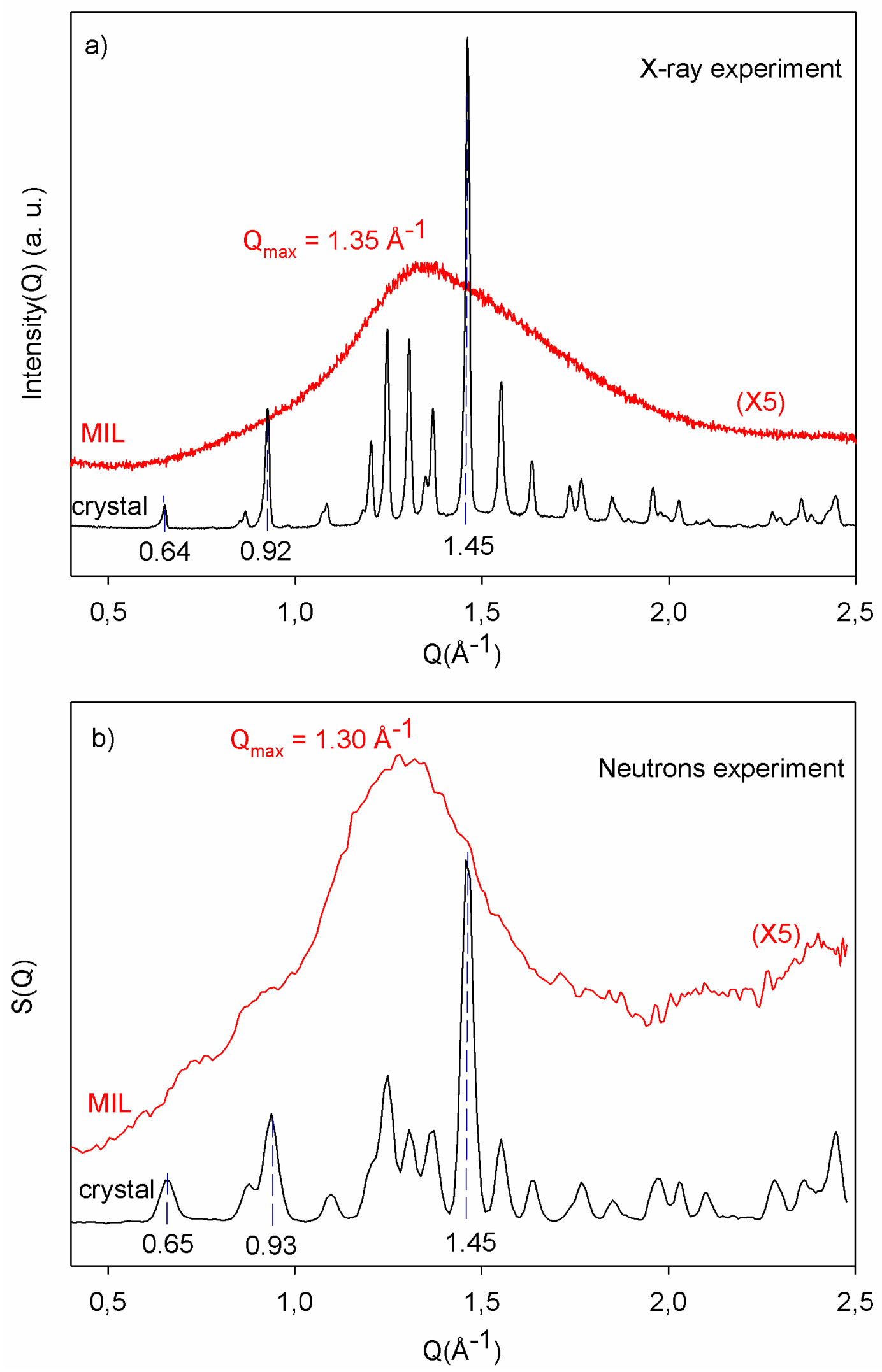
Figure 6: X-ray (a) and neutron (b) diffraction patterns of MIL lactulose (red line) and crystalline lactulose (black line) recorded at RT. The diffraction patterns of the MIL lactulose have been multiplied by 5 compared to those of the crystalline lactulose.

Table 1: Position, height and width of the FDP of the different amorphous samples. QFDP (peak position) is the Q coordinate of the maximum intensity of the FDP, AFDP (peak height) corresponds to the maximum intensity of the FDP and $\Delta_{\text {FDP }}$ (peak width) is the full width at the half maximum intensity of the FDP.

\begin{tabular}{|l|l|l|l|}
\hline Samples & $\begin{array}{l}\text { QFDP (peak } \\
\left.\text { position, } \pm 0.03 \AA^{-1}\right)\end{array}$ & $\begin{array}{l}\text { AFDP (peak height, } \\
\pm 0.01 \text { a. u. })\end{array}$ & $\begin{array}{l}\Delta_{\text {FDP }} \text { peak width, } \\
\left. \pm 0.02 \AA^{-1}\right)\end{array}$ \\
\hline MIL & 1.30 & 1.42 & 0.40 \\
\hline QM & 1.30 & 1.37 & 0.30 \\
\hline FD & 1.30 & 1.38 & 0.34 \\
\hline SD & 1.30 & 1.39 & 0.35 \\
\hline
\end{tabular}

\section{c- Microstructural features and quantitative phase analysis of the crystalline and MIL compound}

To assess the microstructures of the crystalline powder and the MIL sample, we performed a Rietveld analysis of their diffraction patterns using the MAUD software ${ }^{79}$. Rietveld analysis is based on a comparison between a simulated neutron pattern and an experimental one by minimising for example the intensity R-factor $R_{\mathrm{I}}$ (case of the MAUD software) on the whole diagram:

$R_{I}=\sum_{i} \frac{I_{i}^{\text {exp }}-I_{i}^{\text {sim }}}{I_{i}^{\text {exp }}} \quad$ Eq. 3

where $I_{i}^{\text {exp }}$ and $I_{i}^{\text {sim }}$ are the intensities of the experimental and simulated neutron patterns at point i, (see Ref. ${ }^{80}$ for details on the simulation). It is generally considered that a $R_{\mathrm{I}}$ ratio below $15 \%$ is sufficiently good for low-symmetry crystals such as crystalline lactulose ${ }^{80}$. The $I_{i}^{\text {exp }}$ peak position and shape depend on lattice parameters and structural defects such as crystallite size, while the background and the peak intensities depend on the amorphous content.

For each diagram, two Rietveld refinements were performed using slightly different starting parameters to improve the resulting solution. The reference structures used, i.e. the starting parameters of $I_{i}^{\text {sim }}$, were those of the BOBKUY10 cif files in the Cambridge Structural Database (CSD) library for the crystalline powder, and those obtained from the QM diffraction patterns (QM sample is considered fully amorphous) ${ }^{81}$ for the amorphous system. 
The instrumental resolution function, determined using Bragg diffraction from a standard Yttrium Iron Garnet sample ${ }^{82}$, was implemented in MAUD through the Cagliotti parameters and used to determine the lattice parameters and the crystallite sizes of the crystals.

The analysis for the fully crystalline sample gives a crystallite size of about $100 \mathrm{~nm}$. This is consistent with results obtained on crystalline trehalose probed by synchrotron diffraction ${ }^{83}$, where crystallites of about $100 \mathrm{~nm}$ were also detected.

The same analysis performed on the MIL compound shows the presence of remaining crystallites. Those crystallites are present in a ratio of 1-4\%, and their sizes are between 20-30 $\mathrm{nm}$. It is interesting to note that despite the long milling time of 8 hours, it was not possible to obtain crystallites smaller than $20 \mathrm{~nm}$. This is in agreement with results obtained by Dujardin et al. ${ }^{84}$ who showed for several crystalline samples ( $\alpha$-glucose, lactose, trehalose, indomethacin, etc) that the sizes of the crystallites decrease upon milling down to a limiting value of about $20 \mathrm{~nm}$.

For completeness, we performed a fast DSC experiment on the MIL compound, which also shows a small crystalline fraction. The obtained results are shown in the Supplementary Material.

\section{d- Impact of the tautomeric composition on the static structure factor}

Figure 7 shows the static structure factor calculated from MD simulation close to the FDP for the different tautomers. The differences between the different tautomers are more important in this low Q-region, as compared to higher Q-regions (Figure 4). The experimental static structure factor of an amorphous sample is also added for comparison. Since the $S(Q)$ of amorphous samples are similar, we have arbitrary chosen to plot the FD sample.

There is a fairly good agreement between experimental and numerical peak positions and widths. Small differences are however found in peak height. This could be due to difficulties for the force field ${ }^{64,65}$ to model intermolecular interactions very well, thus inducing a poor estimation of $\mathrm{S}(\mathrm{Q})$ at low $\mathrm{Q}(\mathrm{S}(\mathrm{Q})$ is underestimated at low $\mathrm{Q}$, leading to an overestimation of peak height). Similarly to what was observed in the medium Q region (Figure 4), the peak position for tautomer $\mathrm{C}$ is slightly shifted to lower $\mathrm{Q}$ values, likely for topological reasons. In addition, the calculation of the gyrations radius has shown that tautomers $\mathrm{A}$ and $\mathrm{B}$ are slightly smaller than tautomer $\mathrm{C}^{55}$. 


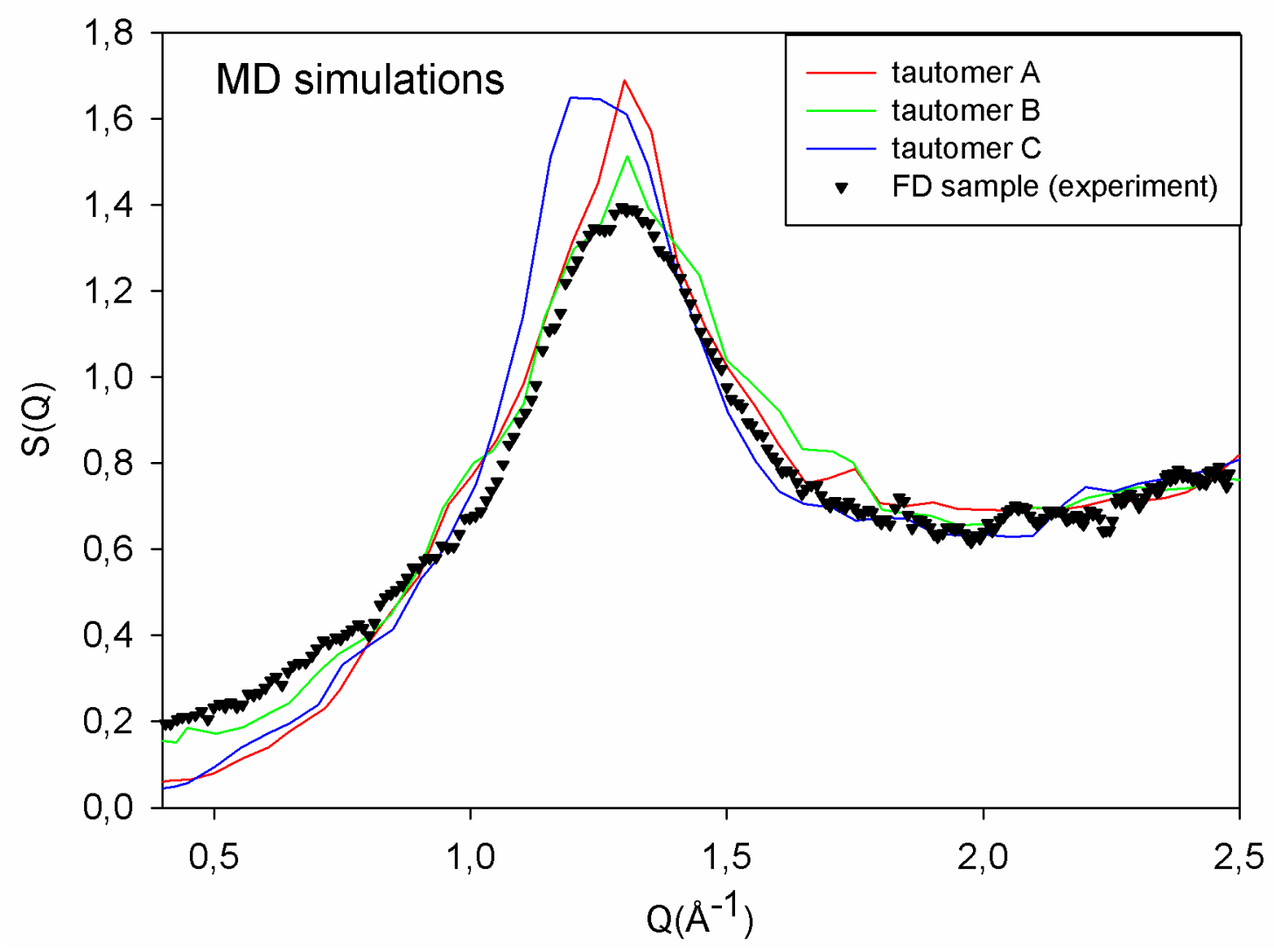

Figure 7: FDP of lactulose tautomer A (red line), tautomer B (green line) and tautomer C (blue line) calculated using Eq. 1. The error bar on the $\mathrm{Q}$ position as determined by MD simulations is about $0.05 \AA^{-1}$. The experimental static structure factor of one of the amorphous samples, arbitrary FD sample (black triangles down), is also included for comparison. 


\section{Summary and Conclusion}

By means of scanning electron microscopy, polarised neutron diffraction and MD simulations, different amorphous lactulose compounds have been investigated. Four different amorphisation processes have been used: the quench of the melt form, the milling of the anhydrous crystal, the spray-drying and the freeze-drying. Complementary studies of anhydrous crystalline lactulose were also performed.

Major differences on the morphology of the different amorphous samples have been revealed from scanning electron microscopy. The milled lactulose particles are oval-shaped and tend to aggregate. Their shape differs from that of the crystal, indicating an amorphisation of the crystal during milling. The spray-dried lactulose particles are all ovoid while the freeze-dried lactulose particles have a flake-like morphology. All these differences of morphology should impact strongly on the physico-chemical properties of the amorphous compounds such as the dissolution rate.

Subtle structural and microstructural differences have been observed between the amorphous compounds from polarised neutron scattering. Microstructure of the milled sample appears slightly different from the other amorphised materials. This difference comes from the presence of residual crystalline germs in the milled sample. Those crystalline germs detected by neutron diffraction where not detected by X-ray diffraction, showing the advantage of neutron scattering in this case. Quantitative phase analysis shows that these remaining crystalline germs are present in a ratio between 1-4\%, and their size remains between 20-30 $\mathrm{nm}$ despite a long milling time of about 8 hours. The detection limits of small crystallites are not the same in the different techniques (X-ray, DSC, neutron scattering), and one should always be careful when analysing milled compounds. Not seeing crystallites by an experimental technique does not necessary mean that the sample is totally free of crystallites. There might be small remaining crystallites, detectable by another technique, which might have an impact on the physical stability of the compound.

The spray-dried and freeze-dried samples appear more disordered than the quenched melt sample. The difference in tautomeric concentrations of the different amorphous sample is shown to have an impact on their structural properties from molecular dynamics simulations. These chemical changes actually explain the small structural differences between the quenched melt, spray-dried and freeze-dried samples, which are all fully amorphous. No comparison can be made on the structure of the amorphous part of the milled compound, due to remaining crystallites.

To the best of our knowledge, for the first time, neutron static structure factors of amorphous hydrogenous solid compounds have been measured at high-Q range on non-deuterated compounds. This has been done thanks to the D3 diffractometer. The results are however too noisy to perform PDF analysis, although instruments upgrade may in the future allow it. In the meantime, this will motivate further synchrotron diffraction experiments, although X-rays are little sensitive to hydrogen, contrarily to neutrons. PDF analysis should give more structural information on the samples. 
All the morphological, structural and microstructural differences detected during this study are likely to impact the physical stability and the dissolution rate of the amorphous compounds. Further experiments will be performed to investigate those properties.

\section{Acknowledgment}

The authors acknowledge the use of the facilities of the CRI (Villeneuve d'Ascq, France) where some calculations were carried out. The beam time provided by ILL is gratefully acknowledged (ILL data DOIs: 10.5291/ILL-DATA.6-05-967 (D3); 10.5291/ILL-DATA.605-974 (D7)). This project has received funding from the Interreg 2 Seas programme 20142020 co-funded by the European Regional Development Fund under subsidy contract 2S01059_IMODE.

F. NGONO thanks the ILL PhD program and the University of Lille for their financial support.

Supporting Information Available: Two figures are represented. One figure shows the diffraction patterns of the different compounds as measured on D7 diffractometer, with the experimental error bars represented. The other figure shows fast DSC scan performed on a MIL compound in order to detect the few remaining crystallites. 
For Table of Contents Only

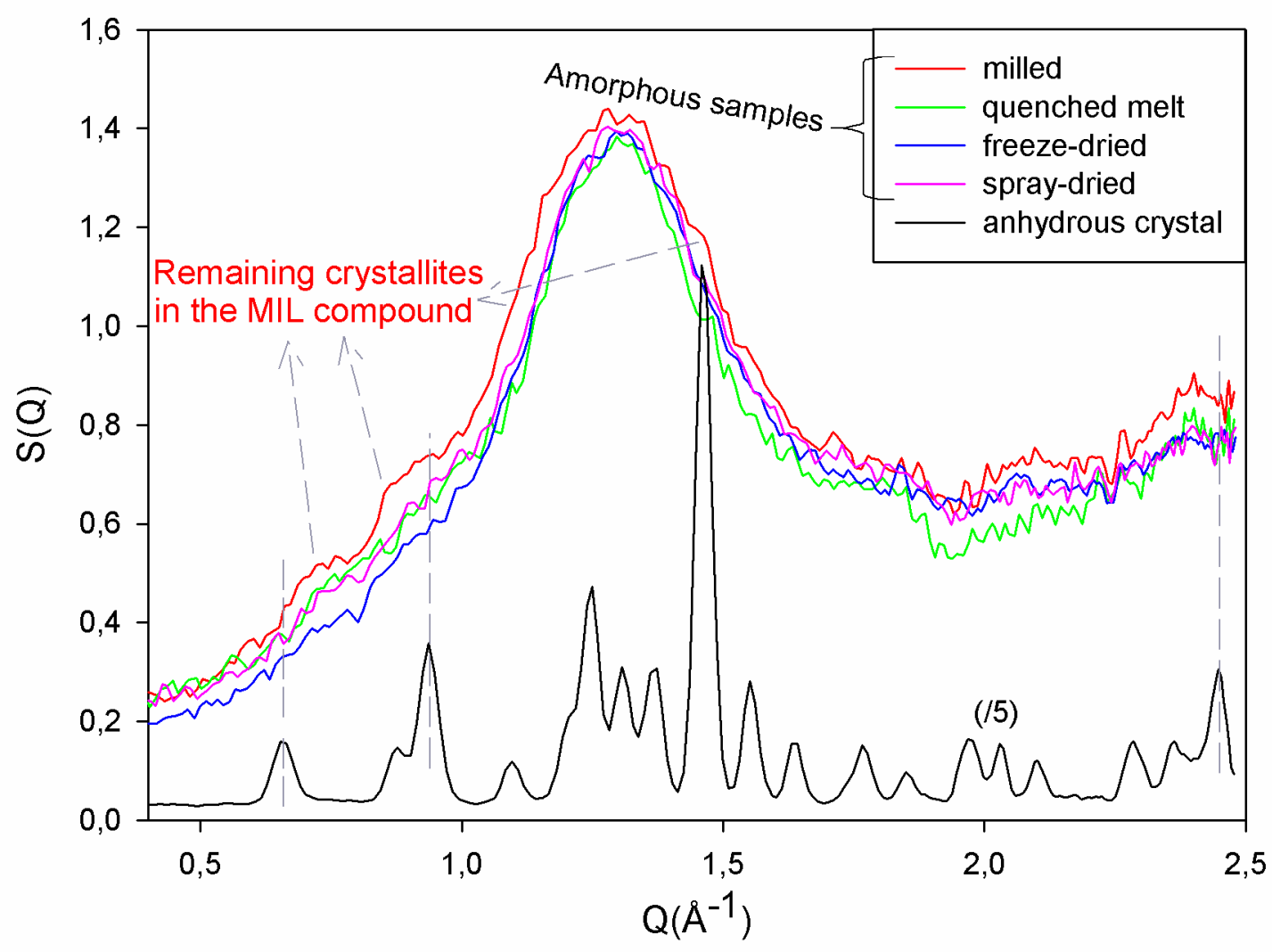

STRUCTURE OF AMORPHISED LACTULOSE SAMPLES

(D7 diffraction experiment) 
1. Descamps M, Willart JF. Some Facets of Molecular Disorder in Crystalline and Amorphous Pharmaceuticals. In: Disordered Pharmaceutical Materials. Wiley-VCH Verlag; 2016:1-56.

2. Willart JF, Descamps M. Solid state amorphization of pharmaceuticals. Mol Pharm. 2008;5(6):905-920. doi:10.1021/mp800092t

3. Savjani KT, Gajjar AK, Savjani JK. Drug Solubility: Importance and Enhancement Techniques. ISRN Pharm. 2012;2012:1-10. doi:10.5402/2012/195727

4. Murdande SB, Pikal MJ, Shanker RM, Bogner RH. Solubility advantage of amorphous pharmaceuticals: I. A thermodynamic analysis. J Pharm Sci. 2010;99(3):1254-1264.

5. Bahl D, Hudak J, Bogner RH. Comparison of the ability of various pharmaceutical silicates to amorphize and enhance dissolution of indomethacine upon co-grinding. Pharm Dev Technol. 2008;13(3):255-269.

6. Debenedetti PG. Metastable Liquids Concepts and Principles. Princeton University Press; 1996.

7. Graeser KA, Patterson JE, Rades T. Physical stability of amorphous drugs: Evaluation of thermodynamic and kinetic parameters. J Pharm Pharmacol. 2008;60:116.

8. Bhattacharya S, Suryanarayanan R. Local mobility in amorphous pharmaceuticalscharacterization and implications on stability. J Pharm Sci. 2009;98(9):2935-2953. doi:10.1002/jps.21728

9. Hancock BC, Zografi G. Characteristics and significance of the amorphous state in pharmaceutical systems. J Pharm Sci. 1997;86(1):1-12.

10. Hancock BC, Parks M. What is the true solubility advantage for amorphous pharmaceuticals? Pharm Res. 2000;17(4):397-404.

11. Baird JA, Taylor LS. Evaluation of amorphous solid dispersion properties using thermal analysis techniques. Adv Drug Deliv Rev. 2012;64(5):396-421.

12. Einfal T, Planinšek O, Hrovat K. Methods of amorphization and investigation of the amorphous state. Acta Pharm. 2013;63(3):305-334. doi:10.2478/acph-2013-0026

13. Descamps M, Willart JF. Perspectives on the amorphisation/milling relationship in pharmaceutical materials. Adv Drug Deliv Rev. 2016;100:51-66.

14. Brittain HG. Effects of mechanical processing on phase composition. J Pharm Sci. 2002;91(7):1573-1580.

15. Balaz P, Achimovicova M, Balaz M, et al. Hallmarks of mechanochemistry: from nanoparticles to technology. Chem Soc Rev. 2013;42(18):7571-7637.

16. Takacs L. The historical development of mechanochemistry. Chem Soc Rev. 2013;42(18):7649-7659.

17. Suryanarayana C. Mechanical Alloying And Milling. Marcel Dekker Incorporated; 2004.

18. Willart JF, De Gusseme A, Hemon S, Descamps M, Leveiller F, Rameau A. Vitrification and polymorphism of trehalose induced by dehydration of trehalose dihydrate. J Phys Chem B. 2002;106(13):3365-3370. doi:10.1021/jp012836+

19. Onodera N, Suga H, Seki S. Glass transition in dehydrated amorphous solid. Bull Chem Soc Jpn. 1968;41:2222.

20. Dujardin N, Willart JF, Dudognon E, et al. Solid state vitrification of crystalline $\alpha$ and $\beta$-D-glucose by mechanical milling. Solid State Commun. 2008;148(1-2):78-82. doi:10.1016/j.ssc.2008.07.002

21. Willart JF, Caron V, Lefort R, Danede F, Prevost D, Descamps M. Athermal character of the solid state amorphization of lactose induced by ball milling. Solid State Commun. 2004;132(10):693-696.

22. Dujardin N, Dudognon E, Willart JF, et al. Solid state mutarotation of glucose. J Phys Chem B. 2011;115(7):1698-1705. doi:10.1021/jp109382j 
23. Descamps M, Willart JF, Dudognon E, Caron V. Transformation of pharmaceutical compounds upon milling and comilling: The role of Tg. J Pharm Sci. 2007;96(5):13981407.

24. Debenedetti PG, Stillinger FH. Supercooled liquids and the glass transition. Nature. 2001;410(6825):259-267. doi:10.1038/35065704

25. Ediger MD, Angell CA, Nagel SR. Supercooled Liquids and Glasses. J Phys Chem. 1996;100(31):13200-13212. doi:10.1021/jp953538d

26. Crowley MM, Zhang F, Repka MA, et al. Pharmaceutical applications of hot-melt extrusion: Part I. Drug Dev Ind Pharm. 2007;33(9):909-926.

27. Tang X, Pikal MJ. Design of freeze-drying processes for pharmaceuticals: practical advice. Pharm Res. 2004;21(2):191-200.

http://www.ncbi.nlm.nih.gov/pubmed/15032301.

28. Broadhead J, Edmond Rouan SK, Rhodes CT. The spray drying of pharmaceuticals. Drug Dev Ind Pharm. 1992;18(11-12):1169-1206. doi:10.3109/03639049209046327

29. Singh A, Van den Mooter G. Spray drying formulation of amorphous solid dispersions. Adv Drug Deliv Rev. 2016;100:27-50. doi:10.1016/j.addr.2015.12.010

30. Qian L, Zhang H. Controlled freezing and freeze drying: a versatile route for porous and micro-/nano-structured materials. J Chem Technol Biotechnol. 2011;86(2):172184. doi:10.1002/jctb. 2495

31. Hu J, Johnston KP, Williams RO. Rapid dissolving high potency danazol powders produced by spray freezing into liquid process. Int J Pharm. 2004;271(1-2):145-154. http://www.ncbi.nlm.nih.gov/pubmed/15129981.

32. Patterson JE, James MB, Forster AH, Lancaster RW, Butler JM, Rades T. Preparation of glass solutions of three poorly water soluble drugs by spray drying, melt extrusion and ball milling. Int J Pharm. 2007;336(1):22-34. doi:10.1016/j.ijpharm.2006.11.030

33. Mishima O, Calvert LD, Whalley E. An apparently first-order transition between two amorphous phases of ice induced by pressure. Nature. 1985;314(6006):76-78. doi:10.1038/314076a0

34. Stanley HE, Mishima O. The relationship between liquid, supercooled and glassy water. Nature. 1998;396(6709):329-335. doi:10.1038/24540

35. Zhu M, Wang JQ, Perepezko JH, Yu L. Possible existence of two amorphous phases of d -mannitol related by a first-order transition. J Chem Phys. 2015;142(24). doi:10.1063/1.4922543

36. Zhu M, Yu L. Polyamorphism of D-mannitol. J Chem Phys. 2017;146(24). doi:10.1063/1.4989961

37. Guinet Y, Paccou L, Danède F, Willart JF, Derollez P, Hédoux A. Comparison of amorphous states prepared by melt-quenching and cryomilling polymorphs of carbamazepine. Int J Pharm. 2016;509(1-2):305-313. doi:10.1016/j.ijpharm.2016.05.050

38. Surana R, Pyne A, Suryanarayanan R. Effect of Preparation Method on the Physical Properties of Amorphous Trehalose. 2004;21(5).

39. Bhardwaj SP, Suryanarayanan R. Molecular Mobility as an Effective Predictor of the Physical Stability of Amorphous Trehalose. Mol Pharm. 2012;9(11):3209-3217. doi:10.1021/mp300302g

40. Bhugra C, Rambhatla S, Bakri A, et al. Prediction of the Onset of Crystallization of Amorphous Sucrose Below the Calorimetric Glass Transition Temperature from Correlations with Mobility. J Pharm Sci. 2007;96(5):1258-1269. doi:10.1002/jps.20918

41. Schammé B, Monnier X, Couvrat N, et al. Insights on the Physical State Reached by an Active Pharmaceutical Ingredient upon High-Energy Milling. J Phys Chem B. 
2017;121(19):5142-5150. doi:10.1021/acs.jpcb.7b02247

42. Bhugra C, Shmeis R, Krill SL, Pikal MJ. Prediction of Onset of Crystallization from Experimental Relaxation Times. II. Comparison between Predicted and Experimental Onset Times. J Pharm Sci. 2008;97(1):455-472. doi:10.1002/jps.21162

43. Bhugra C, Shmeis R, Pikal MJ. Role of Mechanical Stress in Crystallization and Relaxation Behavior of Amorphous Indomethacin. J Pharm Sci. 2008;97(10):44464458. doi:10.1002/jps.21291

44. CHIENG N. Formation and physical stability of the amorphous phase of ranitidine hydrochloride polymorphs prepared by cryo-milling. Eur J Pharm Biopharm. 2008;68(3):771-780. doi:10.1016/j.ejpb.2007.09.001

45. Kothari K, Ragoonanan V, Suryanarayanan R. Influence of Molecular Mobility on the Physical Stability of Amorphous Pharmaceuticals in the Supercooled and Glassy States. Mol Pharm. 2014;11(9):3048-3055. doi:10.1021/mp500229d

46. Murty BS, Datta MK, Pabi SK. Structure and thermal stability of nanocrystalline materials. Sadhana - Acad Proc Eng Sci. 2003;28(1-2):23-45. doi:10.1007/BF02717124

47. Aït-Aissa A, Aïder M. Lactulose: production and use in functional food, medical and pharmaceutical applications. Practical and critical review. Int J Food Sci Technol. 2014;49(5):1245-1253. doi:10.1111/ijfs. 12465

48. Patil DH, Westaby D, Mahida YR, et al. Comparative modes of action of lactitol and lactulose in the treatment of hepatic encephalopathy. Gut. 1987;28(3):255-259. doi:3570029

49. Kaminski K, Kaminska E, Wlodarczyk P, et al. Dielectric studies on mobility of the glycosidic linkage in seven disaccharides. J Phys Chem B. 2008;112(40):12816-12823. doi:10.1021/jp804240a

50. Nelson JM, Beegle FM. MUTAROTATION OF GLUCOSE AND FRUCTOSE. $J$ Am Chem Soc. 1919;41(4):559-575. doi:10.1021/ja01461a007

51. Lefort R, Caron V, Willart J-F, Descamps M. Mutarotational kinetics and glass transition of lactose. Solid State Commun. 2006;140(7-8):329-334. doi:10.1016/j.ssc.2006.09.003

52. Acree TE, Shallenberger R s., Lee CY, Einset JW. Thermodynamics and kinetics of Dgalactose tautomers during mutarotation. Carbohydr Res. 1969;10(3):355-360. doi:10.1016/S0008-6215(00)80894-0

53. Jeffrey GA, Wood RA, Pfeffer PE, Hicks KB. Crystal structure and solid-state NMR analysis of lactulose. J Am Chem Soc. 1983;105(8):2128-2133. doi:10.1021/ja00346a005

54. Jeffrey GA, Huang DB, Pfeffer PE, Dudley RL, Hicks KB, Nitsch E. Crystal structure and n.m.r. analysis of lactulose trihydrate. Carbohydr Res. 1992;226(1):29-42. http://www.ncbi.nlm.nih.gov/pubmed/1499020.

55. Ngono F, Willart J-F, Cuello G, Jimenez-Ruiz M, Hamoudi M-C, Affouard F. Impact of amorphisation methods on the physico-chemical properties of amorphous lactulose. Submitt to Mol Pharm. 2019.

56. Ngono F, Willart J-F, Cuello G, Jimenez-Ruiz M, Affouard F. Lactulose: A Model System to Investigate Solid State Amorphization Induced by Milling. J Pharm Sci. September 2018. doi:10.1016/j.xphs.2018.09.013

57. Stunault A, Vial S, Jullien D, Cuello GJ. D3 at the ILL: Structural studies of hydrogenous liquid and amorphous systems. Phys B Condens Matter. 2018;551:373376. doi:10.1016/j.physb.2017.10.130

58. Stewart JR, Deen PP, Andersen KH, et al. Disordered materials studied using neutron polarization analysis on the multi-detector spectrometer, D7. J Appl Crystallogr. 
2009;42(1):69-84. doi:10.1107/S0021889808039162

59. Stunault A, Vial S, Pusztai L, Cuello GJ, Temleitner L. Structure of hydrogenous liquids: separation of coherent and incoherent cross sections using polarised neutrons. $J$ Phys Conf Ser. 2016;711(1):012003. doi:10.1088/1742-6596/711/1/012003

60. Rodríguez Palomino LA, Cuello GJ, Stunault A, Dawidowski J. Structure factor determination of deuterated 1- and 2-propanol using diffraction experiments with polarization analysis. Philos Mag. 2016;96(7-9):816-827. doi:10.1080/14786435.2015.1102350

61. Fischer HE, Barnes AC, Salmon PS. Neutron and x-ray diffraction studies of liquids and glasses. Reports Prog Phys. 2006;69(1):233-299. doi:10.1088/0034-4885/69/1/R05

62. Wildes AR. Scientific Reviews: Neutron Polarization Analysis Corrections Made Easy. Neutron News. 2006;17(2):17-25. doi:10.1080/10448630600668738

63. Todorov IT, Smith W, Trachenko K, Dove MT. DL_POLY_3: new dimensions in molecular dynamics simulations via massive parallelism. J Mater Chem. 2006;16(20):1911. doi:10.1039/b517931a

64. Jorgensen WL, Maxwell DS, Tirado-Rives J. Development and Testing of the OLPS All-Atom Force Field on Conformational Energetics and Properties of Organic Liquids. J Am Chem Soc. 1996;118(15):11225-11236. doi:10.1021/ja9621760

65. Kaminski GA, Friesner RA, Tirado-Rives J, Jorgensen WL. Evaluation and reparametrization of the OPLS-AA force field for proteins via comparison with accurate quantum chemical calculations on peptides. $J$ Phys Chem B. 2001;105(28):6474-6487. doi:10.1021/jp003919d

66. Shamblin SL, Taylor LS, Zografi G. Mixing Behavior of Colyophilized Binary Systems. J Pharm Sci. 1998;87(6):694-701. doi:10.1021/JS9704801

67. Naoki M, Ujita K, Kashima S. Pressure-volume-temperature relations and configurational energy of liquid, crystal, and glasses of D-sorbitol. J Phys Chem. 1993;97(47):12356-12362. doi:10.1021/j100149a042

68. Imamura K, Maruyama Y, Tanaka K, Yokoyama T, Imanaka H, Nakanishi K. True density analysis of a freeze-dried amorphous sugar matrix. J Pharm Sci. 2008;97(7):2789-2797. doi:10.1002/jps.21202

69. Dove MT. Introduction to the theory of lattice dynamics. École thématique la Société Française la Neutron. 2011;12:123-159. doi:10.1051/sfn/201112007

70. Vehring R. Pharmaceutical particle engineering via spray drying. Pharm Res. 2008;25(5):999-1022. doi:10.1007/s11095-007-9475-1

71. Aundhia CJ, Raval JA, Patel MM, et al. Spray Drying in the Pharmaceutical Industry A Review. Indo Am J Pharm Res Indo Am J Pharm Res Aundhia CJ al Indo Am J Pharm Res. 2011;212(111):125-13863. http://www.iajpr.com/index.php/en/.

72. Deng Y, Sun, Wang, et al. Effect of particle size on solubility, dissolution rate, and oral bioavailability: evaluation using coenzyme Q10 as naked nanocrystals. Int J Nanomedicine. 2012;65(1):5733. doi:10.2147/IJN.S34365

73. Haque MK, Roos YH. Differences in the physical state and thermal behavior of spraydried and freeze-dried lactose and lactose/protein mixtures. Innov Food Sci Emerg Technol. 2006;7(1-2):62-73. doi:10.1016/j.ifset.2004.12.004

74. S. J. L. Billinge MFT. Local structure from diffraction. Acta Crystallogr Sect A Found Crystallogr. 1999;55(1):95-95. doi:10.1107/S0108767398012306

75. Billinge SJL, Dykhne T, Juhás $P$, et al. Characterisation of amorphous and nanocrystalline molecular materials by total scattering. CrystEngComm. 2010;12(5):1366-1368. doi:10.1039/b915453a

76. Sears VF. Neutron scattering lengths and cross sections. Neutron News. 1992;3(3):2637. doi:10.1080/10448639208218770 
77. NARTEN AH, THIESSEN WE, BLUM L. Atom Pair Distribution Functions of Liquid Water at 25 C from Neutron Diffraction. Science (80- ). 1982;217(4564):1033-1034. doi:10.1126/science.217.4564.1033

78. Temleitner L, Stunault A, Cuello GJ, Pusztai L. Neutron diffraction of hydrogenous materials: Measuring incoherent and coherent intensities separately. Phys Rev B. 2015;92(1):014201. doi:10.1103/PhysRevB.92.014201

79. Lutterotti L. Total pattern fitting for the combined size-strain-stress-texture determination in thin film diffraction. Nucl Instruments Methods Phys Res Sect B Beam Interact with Mater Atoms. 2010;268(3-4):334-340. doi:10.1016/j.nimb.2009.09.053

80. Young RA. The Rietveld Method. Oxford: IUCr Monographs on Crystallography,Oxford Publications; 1991.

81. Madsen IC, Scarlett NVY, Kern A. Description and survey of methodologies for the determination of amorphous content via X-ray powder diffraction. Zeitschrift für Krist. 2011;226(12):944-955. doi:10.1524/zkri.2011.1437

82. Fennell T, Mangin-Thro L, Mutka H, Nilsen GJ, Wildes AR. Wavevector and energy resolution of the polarized diffuse scattering spectrometer D7. Nucl Instruments Methods Phys Res Sect A Accel Spectrometers, Detect Assoc Equip. 2017;857:24-30. doi:10.1016/j.nima.2017.03.024

83. Bordet P, Bytchkov A, Descamps M, et al. Solid State Amorphization of $\beta$-Trehalose: A Structural Investigation Using Synchrotron Powder Diffraction and PDF Analysis. Cryst Growth Des. 2016;16(8):4547-4558. doi:10.1021/acs.cgd.6b00660

84. Dujardin N, Willart JF, Dudognon E, Danède F, Descamps M. Mechanism of solid state amorphization of glucose upon milling. J Phys Chem B. 2013;117(5):1437-1443. doi:10.1021/jp3069267 